\title{
COMPLEXIDADE DO PROCESSO DE ENSINO-APRENDIZAGEM EM CURSO EAD ON-LINE
}

\author{
COMPLEXITY OF TEACHING AND LEARNING PROCESS IN ONLINE DISTANCE \\ LEARNING COURSE
}

\author{
Eliamar Godoi \\ Universidade Federal de Uberlândia
}

RESUMO: Norteados pela teoria da Complexidade (MORIN, 2003; PAIVA, 2009), investigamos um curso de Letras/Inglês a distância cujas salas de aula on-line foram definidas como ambientes de aprendizagem. Buscamos saber qual a relação entre o projeto pedagógico do curso e o seu design instrucional e, também, quais os fatores contextuais mais importantes que restringiram ou favoreceram a emergência de um ambiente propício à aprendizagem nesse curso. Esse estudo constituiu-se uma pesquisa descritiva de natureza qualitativa do tipo etnográfico. Os dados foram analisados a partir da ressignificação da proposta de Davis e Sumara (2006) sobre condições para emergência da Complexidade em contextos educacionais, alinhada à de Filatro (2007, 2008) sobre a influência de fatores contextuais que favorecem ou restringem o processo de ensino e aprendizagem em contextos on-line. A análise indicou que o projeto pedagógico e o design instrucional do curso foram preparados para um público alvo específico, mas recebeu inesperada diversidade de ingressantes. Concluímos que o curso enquanto sistema deveria ter sido retroalimentado com as informações levantadas a respeito de seus participantes e de seu entorno, possibilitando sua auto-organização. Ao se manter inflexível, não permitindo a integração de energia externa, o curso não se adaptou ao contexto de aplicação, mostrando-se descontextualizado e em processo acelerado de entropia.

PALAVRAS-CHAVE: Ambiente on-line de aprendizagem. Condições para a Complexidade. Fatores contextuais.

ABSTRACT: On the grounds of the theory of Complexity (MORIN, 2003; PAIVA, 2009), we have researched a distance course of Language and Literature (English) in which online classrooms have been defined as learning environments. The goal was to search for the relation between the pedagogical project of the course and its instructional design as well as to identify the most significant contextual factors restricting or favoring the emergence of an environment conductive to learning. As to the type of research, it was descriptive, qualitative and ethnographic-oriented. Data have been analysed according to ressignification of Davis' and Sumara's proposal about the conditions for Complexity emergence in educational contexts aligned to Filatro's ideas $(2007,2008)$ on the influence of contextual factors which may favor or restrict teaching and learning processes in online contexts. The analysis has indicated that course had been targeted to a specific and, at some extent, homogeneous audience, but received unexpected diversity of participants. It is possible to conclude that the course, while a system, should be given feedback with information about its participants, which could prevent itself from collapsing. Because of its inflexibility, the course had not been adapted to the context of application, remaining noncontextualized and in accelerated process of entropy. 


\section{Revista do SELL}

v. $4, n^{\circ} .1$

ISSN: $1983-3873$

KEYWORDS: Online learning environment. Conditions for Complexity. Contextual Factories.

\section{Considerações iniciais}

Entendemos que no campo da educação on-line, a LA tem se configurado como uma espécie de interface que avança zonas fronteiriças de diferentes disciplinas, suscitando novas formas de condução de seus estudos, carecendo ainda de novos instrumentos de reflexão sobre o seu objeto que envolve fenômenos relacionados à língua em uso em contextos diversos, abrangendo seu ensino, aprendizagem, aquisição etc.

Nessa direção, no campo da LA, autores como Paiva (2005) Martins (2008), Braga (2009), Paiva e Nascimento (2009), Resende (2009), Souza (2011) e Teixeira (2012), entre outros, buscaram em teorias da Complexidade e do Caos abordagens investigativas diferenciadas dos modelos já existentes para compreender diversos fenômenos relacionados aos processos de aquisição, de ensino e de aprendizagem de línguas e à própria língua. Acreditamos, nesse caso, que esses autores foram os primeiros linguistas aplicados brasileiros a recorrem às teorias da Complexidade e do Caos para condução de seus trabalhos.

Vetromille-Castro (2009) também adota a perspectiva complexa em sua pesquisa sobre sala de aula de formação de professores de Línguas Estrangeiras - LE ao contemplar os movimentos entre os indivíduos, os elementos que derivam dessas relações e sustentam um sistema complexo de trocas. Para esse autor, a maior parte das pesquisas em LA tem deixado lacunas no que se refere ao seu foco e extensão, além de que, não tem conseguido acompanhar a evolução de novas perspectivas que emergem dentro da própria área. Esse autor destaca a carência de pesquisas em LA, sobretudo, em salas de aula de LE e de formação de professores de LE e aponta a Complexidade como alternativa de condução para pesquisas em LA.

No sentido de entender essa nova perspectiva investigativa, buscamos uma definição do conceito de Complexidade. Morin (2003) define Complexidade como um tecido (complexus: o que é tecido em conjunto) de constituintes heterogêneos inseparavelmente associados que coloca o paradoxo do uno e do múltiplo. Para ele, a Complexidade é efetivamente o tecido de acontecimentos, ações, interações, retroações, determinações, acasos que constituem o nosso mundo fenomenal. Aliada aos princípios 


\section{Revista do SELL}

v. $4, n^{\circ} .1$

ISSN: $1983-3873$

da Complexidade, outra área do conhecimento já bastante conhecida é a Teoria do Caos. Um sistema caótico tem um comportamento que apenas parece ser aleatório, mas na verdade acaba por ser determinístico (LORENZ, 1993).

A Complexidade articula diversas teorias cuja junção compõe um chamado sistema tronco (LEFFA, 2006) e nos leva à denominação de paradigma, nesse caso, Paradigma da Complexidade. O que associa essas teorias, ou seja, o que há de comum entre elas, é o fato de que, em um sistema complexo, tudo está interligado e nada acontece por acaso (LEFFA, 2006). Sendo assim, o Paradigma da Complexidade se tornou um termo guardachuva (SOUZA, 2011) ou um termo valise (SOBRAL, 2011), que recobre ou acolhe diversos campos de estudo.

Partindo do universo da Linguística Aplicada que entende a língua em seus diversos usos (BARCELOS, 2011; SIGNORINI; CAVALCANTI, 2004, FREIRE; ABRAHÃO; BARCELOS, 2005) e pensando a linguagem como princípio organizador do processo ensino e aprendizagem em EAD (MARQUESI; ELIAS; CABRAL, 2008), propomos a investigação de um curso de Letras/Inglês a distância e on-line sob a ótica da Complexidade, indo do planejamento à sua aplicação. Esse curso, denominado Curso de Letras Licenciatura em Inglês e Literaturas de Língua Inglesa - PARFOR - modalidade a distância se constituiu cenário dessa pesquisa. Ele surgiu em caráter especial a partir da adesão da instituição ao Plano Nacional de Formação de Professores da Educação Básica Pública (doravante PARFOR) para capacitar professores em exercício na rede pública que não dispunham de competente habilitação nas disciplinas que ministravam. Nesse curso, a modalidade a distância foi escolhida a fim de se atingir o maior número de pessoas interessadas nesta qualificação.

Sendo assim, buscamos sustentação na vertente da LA que visa compreender melhor a linguagem, as interrelações e as condições de aprendizagem presentes no meio virtual, investigando nesse curso seu processo interativo. Buscamos acompanhar as condições para emergência de um ambiente propício à aprendizagem contextualizada e identificar os fatores contextuais que, em termos de propostas (projeto pedagógico), práticas pedagógicas (atividades e instrução) e das dinâmicas interativas (sala de aula online), evidenciassem contextos favoráveis ou restritivos da aprendizagem no ambiente do curso, quando em seu primeiro semestre de aplicação. Para isso, analisamos a relação entre projeto pedagógico, design instrucional e a sala de aula on-line do curso em que contemplamos os movimentos entre os indivíduos, a interrelação entre seus agentes e 


\section{Revista do SELL}

v. $4, n^{\circ} .1$

ISSN: $1983-3873$

elementos componentes e o que derivou dessas relações que sustentaram o curso, compreendido como sistema adaptativo complexo.

Nesse sentido, enfocar as condições para a emergência de ambiente propício à aprendizagem pode expandir $o$ horizonte de possibilidades para 0 ensino e a aprendizagem em contextos dinâmicos como o AVA. Identificar as condições de emergência e fatores contextuais que influenciam ou restringem a emergência desses ambientes tende a contribuir para uma melhor organização de um design instrucional para que seja cada vez mais eficiente e adequado ao seu contexto de aplicação, além de possibilitar o uso eficiente de estratégias instrucionais na esquematização dos elementos do design. Um design instrucional sensível às condições locais e adaptado a circunstâncias de situação específica do contexto de aplicação minimizará as dificuldades dos agentes que utilizam o meio virtual na busca por conhecimento.

Além disso, conduzir pesquisas que observem a relação complexa entre professores, alunos e o ambiente de aprendizagem pode nos levar a entender os fenômenos que aí ocorrem, possibilitando uma orientação mais consistente e apropriada ao conhecimento e habilidades ensinados e, além de proporcionar um melhor aproveitamento dos recursos didático-pedagógicos dos AVAs com aplicabilidade em cursos de formação de professores de línguas e de ensino de línguas na modalidade a distância.

Nessa perspectiva, nosso estudo se justifica, pois o processo de planejamento e aplicação de um curso de formação de professores de línguas on-line suscita a necessidade premente de acompanhamento dos níveis de planejamento, organização, oferta e efetivação de processos pedagógicos. Como a educação on-line para formação de professores a distância é uma prática relativamente recente, percebe-se que as pesquisas existentes ainda são insuficientes e não têm acompanhado a oferta desses cursos em todas as suas dimensões. Aspectos relevantes como análise das relações que compõem o planejamento e aplicação de um curso e as condições para emergência de ambiente favorável à aprendizagem, sobretudo, no âmbito da formação de professores de línguas a distância não têm sido abarcados pelas atuais pesquisas publicadas.

Minhas experiências com a EAD, na qual atuei como tutora e professora autora e, na atualidade, como professora formadora e graduanda do curso de Pedagogia a distância, alimentaram a ideia para essa pesquisa, a qual foi refinada a partir de discussões realizadas em grupo de seminário temático coordenado pelo Prof. Dr. 


\section{Revista do SELL}

v. $4, n^{\circ} .1$

ISSN: $1983-3873$

Waldenor Barros Moraes Filho e pela Profa ${ }^{a}$. Drª. Valeska Virgínia S. Souza em 2011. Uma vez que minha trajetória como pesquisadora sempre envolveu interesse por linguagem, metodologias de ensino de línguas e tecnologias, mas, sobretudo, pelo que deriva das relações que sustentam os sistemas de ensino e de aprendizagem na área da LA, a ideia de investigar um curso de formação de professores de línguas on-line se mostrou pertinente para que eu conseguisse respostas aos meus questionamentos.

Minha trajetória como pesquisadora sempre foi alimentada pela preocupação e anseio por uma alternativa teórica que conseguisse respostas a meus questionamentos sobre o teor das relações que compunham, organizavam e até conduziam o processo de ensino e aprendizagem em ambiente on-line que envolvesse diversos fenômenos de uso da língua (ensino, aprendizagem, formação de professores de línguas etc.). $E$ foi nas teorias da Complexidade que encontrei a abordagem investigativa que procurava, as quais foram adotadas como alternativas de condução epistemológica para essa pesquisa.

Nesse viés, por meio do olhar múltiplo proposto pelo Paradigma da Complexidade partimos para uma investigação com vistas a perceber como o design instrucional do Curso de Letras/Inglês a Distância (doravante CLIEAD) foi organizado tendo, principalmente, no projeto pedagógico suas condições iniciais. A busca foi por conhecer quais condições poderiam ser propiciadas e/ou articuladas para que o ambiente virtual do curso se caracterizasse como propício e possibilitasse a emergência de aprendizagem. Observamos a natureza das relações entre elementos desse curso e das suas interações, bem como suas potencialidades para os eventos de ensino e aprendizagem nesse contexto, sendo que a Complexidade nos permitiu focalizar mais o processo do que os produtos resultantes desse.

Objetivando encontrar arcabouço teórico que pudesse explicar a qualidade das experiências educacionais no viés da Complexidade nos cenários que propusemos pesquisar, encontramos nos trabalhos de Davis e Sumara (2006), que identificaram e adaptaram para a sala de aula, seis condições necessárias para emergência da Complexidade, fundamentação para nossas análises. Nesse caso, nos apropriamos da proposta desses autores e buscamos analisar o projeto pedagógico, o design instrucional e as salas de aula on-line do CLIEAD à luz dessas condições para emergência da Complexidade propostas por esses autores.

Sendo assim, neste trabalho, utilizamos as seis condições identificadas por Davis e Sumara (2006) como necessárias (embora não suficientes) para que ambientes propícios 


\section{Revista do SELL}

v. $4, n^{\circ} .1$

ISSN: $1983-3873$

à aprendizagem contextualizada (compreendidos como sistemas complexos) possam surgir em ambientes dinâmicos como o CLIEAD, por exemplo. Esses autores identificaram (e adaptaram para a sala de aula) as seguintes condições: diversidade interna, redundância, interações entre vizinhos, controle descentralizado, restrições possibilitadoras e coerência.

Considerando, ainda, o papel do contexto nas relações em um sistema complexo como o CLIEAD, incorporamos a essas condições para a Complexidade alguns fatores contextuais apontados em trabalhos de Filatro $(2007,2008)$. Essa autora identificou e apontou alguns fatores contextuais que podem restringir ou favorecer em diferentes graus os processos de ensino e aprendizagem em ambientes on-line, dentre os quais destacamos: fatores contextuais de caracterização dos agentes, fatores contextuais de orientação, instrução e transferência e os fatores contextuais inibidores, ausentes e facilitadores da aprendizagem.

Partimos do pressuposto de que um ambiente que seja propício à aprendizagem emerge a partir da articulação de diversas condições e a acomodação de vários fatores contextuais em estreita relação com o seu meio de aplicação. Nessa direção, a pretensão foi investigar quais condições foram necessárias para emergência de um ambiente propício à aprendizagem na sala de aula on-line do curso a partir das condições iniciais propostas por seu projeto pedagógico.

Organizado esse arcabouço, buscamos na relação entre projeto pedagógico, design e sala de aula on-line do CLIEAD como as condições para a Complexidade propostas por Davis e Sumara (2006) se estabeleceram no ambiente do curso e como foram acomodados os diversos fatores contextuais que permearam suas ações, permitindo que esse ambiente do curso propiciasse aprendizagem.

Para isso, a partir das propostas organizadas pelo projeto pedagógico do CLIEAD, assumimos como objetivo geral desse estudo, investigar como as condições da Complexidade se estabeleceram no Projeto Pedagógico, no Design Instrucional e nas salas de aula on-line do curso. A análise abrangeu o curso como um todo e, em especial as quatro disciplinas (Introdução à Educação a Distância, Língua Inglesa: Leitura Instrumental, Introdução aos Estudos da Linguagem Integrada à Prática Educativa I, Interdisciplinaridade e Construção do Saber) pertencentes à grade curricular do primeiro semestre de sua implantação. 


\section{Revista do SELL}

v. $4, n^{\circ} .1$

ISSN: $1983-3873$

Assim, três perguntas de pesquisa nortearam o trabalho, quais sejam: Qual a relação entre projeto pedagógico e o design instrucional das diferentes disciplinas do curso? Como as condições necessárias para a emergência da Complexidade identificadas por Davis e Sumara (2006) se estabelecem no projeto pedagógico, no design instrucional e nas salas de aula on-line norteadas pelo contexto? $\mathrm{E}$ quais os fatores contextuais mais importantes restringiram ou favoreceram um ambiente dinâmico e propício à aprendizagem no curso?

O intuito de pesquisa inicial foi analisar as condições necessárias para emergência de ambiente propício à aprendizagem contextualizada. Para isso, as relações complexas concernentes ao curso enquanto um sistema adaptativo recebeu especial atenção. Buscamos amparo no Paradigma da Complexidade, desenvolvendo uma pesquisa descritiva que, pelas suas características, se constituiu como qualitativa (MANN; STEWART, 2000; DENZIN; LINCOLN, 2006, BICUDO, 2011), de orientação etnográfica (van LIER, 2004). Para a análise de dados, fundamentamo-nos em trabalhos de Davis e Sumara (2006) alinhados aos de Filatro (2007, 2008), e no Paradigma da Complexidade, especialmente nos trabalhos de Morin (2003), Martins (2008) e Paiva (2009).

Além desses aspectos introdutórios em que descrevemos e delimitamos a nossa pesquisa e fizemos apontamentos do caminho estratégico de nosso estudo, delineando a constituição de nossos objetivos, na sequência, explicitamos nossas leituras acerca do universo da Educação on-line e alguns conceitos provenientes dessa área que constitui cenário dessa pesquisa, apontamos os caminhos da EAD on-line e da LA que encontraram na Teoria da Complexidade novas formas de condução de pesquisas e de trabalhos nas áreas. Logo depois, apresentamos um pequeno recorte da análise dos dados encontrados no design instrucional do curso feita também à luz das condições necessárias para emergência de um ambiente propício à aprendizagem contextualizada. E, por fim, apresentamos nossas considerações finais para esse artigo, cujo recorte adveio de um trabalho maior organizado em uma Tese de doutoramento em Estudos Linguísticos defendida na Universidade local em 2013.

\subsection{Educação on-line, Complexidade e Linguística Aplicada}

Neste estudo, utilizamos conceitos e pressupostos provenientes da EAD on-line. Trabalhamos, particularmente, com o conceito de EAD on-line que prevê articulação e 


\section{Revista do SELL \\ v. $4, n^{\circ} .1$ \\ ISSN: $1983-3873$}

interrelação dialógica e pedagógica entre agentes, linguagem e tecnologia. Para tanto, relacionamos conceitos de educação on-line pautada nas condições de infraestrutura tecnológica (FILATRO, 2007), em processos pedagógicos específicos (MORAN, 2012) e em interação, em diálogo e intervenção em rede (SILVA, 2012) e chegamos ao que pode ser denominado de EAD on-line.

A educação on-line é demanda da sociedade da informação e compreende um novo modo de produção pautada na informação digitalizada como nova infraestrutura básica. Nessa linha, o computador e a internet definem essa nova ambiência informacional compondo uma nova lógica comunicacional. Para Silva (2012) a educação on-line ganha adesão nesse contexto, garantindo aprendizagem na flexibilidade e na interatividade próprias da internet atraindo cada vez mais instituições, empresas, professores e alunos para essa modalidade educacional.

Nesse caso, de uma perspectiva social para a educação on-line, Silva (2002, p. 11) defende que

a educação on-line é fenômeno da cibercultura, isto é, do conjunto imbricado de técnicas, práticas, atitudes, modos de pensamento e valores que se desenvolvem com o crescimento do ciberespaço ${ }^{1}$. Por esse termo entenda-se 0 novo ambiente comunicacional que surge com a interconexão mundial de computadores e das memórias dos computadores; principal suporte de trocas e de memória da humanidade a partir do século XXI.

Silva (2012) acentua que a flexibilidade e a interatividade, próprias do computador conectado à Internet, são fatores determinantes para o crescimento da educação on-line. No contexto da educação on-line, "o aprendiz encontra em um computador conectado a possibilidade de intervenção nos fluxos de informação e nos processos de aprendizagem, podendo atuar individual e colaborativamente na construção do conhecimento" (SILVA, 2012, p. 12). De um modo geral, esses conceitos apontam para um fazer educação a distância de modo interativo, cooperativo, autônomo e incorporando tecnologia.

Nessa perspectiva, pela sua interatividade, o ambiente virtual ou a sala de aula online permitir-nos-á identificar diversos níveis de interação, de aprendizagem, acesso à informação e à instrução pedagógica constituindo-se um sistema complexo com elementos indissociavelmente interligados. Pelo fato de esse espaço virtual de aprendizagem, enquanto sistema complexo, propiciar acesso a informações em rede,

\footnotetext{
${ }^{1}$ Pode-se encontrar uma boa descrição das expressões ‘cibercultura' e ‘ciberespaço’ em Lévy (1999).
} 


\section{Revista do SELL \\ v. $4, n^{\circ} .1$ \\ ISSN: $1983-3873$}

esses níveis de incorporação de tecnologia vão desde o acesso individual a informações inalteráveis até a imersão total em um ambiente de prática, por um professor e/ou tutor e apoiado por uma comunidade de aprendizagem.

Morin (2003) defende a necessidade de substituir o paradigma da disjunção/redução/unidimensionalização por um paradigma de distinção/conjunção que permita distinguir sem separar, associar sem identificar ou reduzir. Esse autor apresenta o Paradigma da Complexidade como possibilidade de substituição ao paradigma do pensamento simplificador. Para ele, o Paradigma da Complexidade

comportaria um princípio dialógico e translógico, que integraria a lógica clássica tendo simultaneamente em conta seus limites - problemas de contradição, limites de formalismo - traria nele o princípio do uno no múltiplo, que escapa à unidade abstrata do alto (holismo) e do baixo (reducionismo) (MORIN, 2003, p. 22).

Segundo Morin (2003), apenas o pensamento complexo nos permitirá civilizar o nosso conhecimento. O pensamento complexo se constitui assim um termo-valise que recobre e atende uma multiplicidade de estudos permitindo afastar o pesquisador do pensamento simplificador que, segundo Morin (2003), é incapaz de conceber a conjunção do uno no múltiplo. O pensamento complexo não anula a diversidade nem unifica abstratamente, ao contrário, ele justapõe a diversidade sem conceber a unidade.

O Paradigma da Complexidade apresenta princípios que nos direcionam a pensar a Complexidade dos fenômenos e estabelece uma base epistemológica consistente para a compreensão dos contextos e eventos envolvidos no processo de ensino e aprendizagem do CLIEAD. O Paradigma da Complexidade reside em ao menos duas condições: "na variedade das regularidades e no fato de que nem tudo pode ser considerado como regular" (MORIN, 2002, p. 45).

De acordo com Morin (2003), o Paradigma da Complexidade surgirá do conjunto de novas concepções, de novas visões, de novas descobertas e de novas reflexões que vão conciliar-se e juntar-se. Nesse caso, os princípios do pensamento complexo serão necessariamente princípios de distinção, de conjunção e de implicação que estarão presentes no mundo biológico e no mundo sociológico.

Na perspectiva da Linguística Aplicada, apontamos que, considerada uma área do saber que teve seus princípios expandidos e suas fronteiras alargadas (KLEIMAN; CAVALCANTI, 2007), a nosso ver, a Linguística Aplicada, universo de onde parte nossa pesquisa, pode ser vista também em toda sua diversidade, na totalidade de aspectos, 


\section{Revista do SELL}

v. $4, n^{\circ} .1$

ISSN: $1983-3873$

facetas, faces e fases pela lente da Complexidade. Nessa perspectiva, a Linguística Aplicada - LA pode ser entendida como uma área de investigação interdisciplinar que se centra na resolução de problemas da prática de uso da linguagem dentro e fora da sala de aula, ou seja, uma visão que traz implícita a preocupação com problemas de uso da linguagem situados em contextos da práxis humana (MOITA LOPES, 1992).

A LA tem se configurado como uma espécie de interface que avança zonas fronteiriças de diferentes disciplinas. Estudos como os de Kleiman, 1992, Moita Lopes (2006), Kleiman e Cavalcanti (2007), demonstram que essa grande área há muito tempo carecia de uma forma que conduzisse os estudos sem incorrer em reducionismos ou holismos, carecendo ainda de novos instrumentos de reflexão sobre o seu objeto de estudo. Ao percorrer trajetos transdisciplinares, a LA se encontra em processo de deslocamento suscitando uma reconfiguração em seu campo epistemológico e apontando para novos vieses para construção e análise do objeto de investigação encontrando na Complexidade uma seara farta e adequada para condução de seus estudos e descrição dos seus fenômenos.

\subsection{Metodologia}

Nossa investigação se constitui como uma pesquisa empírica, cujos dados foram coletados no AVA do CLIEAD, evidenciando a emergência da Complexidade em contexto on-line. Trata-se de uma abordagem qualitativa, descritiva, de natureza etnográfica tendo em vista uma compreensão holística, mas também pontual, das perspectivas e experiências dos participantes do curso. Essa abordagem se alinha às ideias de autores como Morin (2003), Paiva e Nascimento (2009), Behar (2009) e Signorini; Cavalcanti (2010) que apontam a necessidade de uma visão mais integrada, transdisciplinar, sistêmica, pautada na aprendizagem colaborativa e autônoma, priorizando mais o processo que o produto resultante desse.

Esse estudo encontrou no pensamento complexo (MORIN, 2003) mais uma alternativa de condução da pesquisa. Nesse viés, Silva (2008) acrescenta que a ciência da Complexidade não se configura apenas em uma teoria, mas também num método, não apenas em um cânone de crenças, mas também em uma maneira de se produzir ciência. Nossas leituras mostraram que inúmeros estudiosos (BRAGA, 2007; MARTINS, 2008, SILVA, 2008, PAIVA, 2009; SOUZA, 2011, entre outros.) têm buscado por lentes que 


\section{Revista do SELL \\ v. $4, n^{\circ} .1$ \\ ISSN: $1983-3873$}

possibilitem perceber toda a Complexidade que envolve a EAD, sobretudo, partindo do universo da Linguística Aplicada.

O CLIEAD, compreendido como sistema complexo, se constituiu em um contexto organizado e sistemático, sobretudo, por ser materializado por linguagem escrita. Sendo assim, a perspectiva complexa e qualitativa adotada nesse estudo utilizou procedimentos investigativos que consideraram toda a Complexidade e a inter-relação dos processos que se combinaram para produzir um ambiente educacional virtual (BEHAR, 2009; PAIVA, 2009; BRAGA, 2009).

Partindo do universo da Linguística Aplicada, interessou-nos também a proposta de van Lier (2004), um estudioso da relação entre língua e meio ambiente e de teorias socioculturais que relacionam língua e educação. Para ele, educação e linguística apontam para um novo campo do conhecimento denominado Linguística Educacional e suscita uma abordagem qualitativa para conduzir a coleta e análise dos dados. Esse autor esclarece que todo trabalho que considera fatores como espaço e tempo na relação entre o organismo e meio se constitui como uma forma de pesquisa contextualizada, situada e qualitativa. Segundo van Lier (2004), esse tipo de trabalho é frequentemente associado a um trabalho longitudinal descritivo/interpretativo com a etnografia.

A etnografia proposta por van Lier (2004) segue a ideia do estudo de ciclos para indicar certa delimitação do fenômeno estudado, entretanto, ele considera que a extensão da noção de ciclo é arbitrária, já que os limites são determinados, muitas vezes, de modo a obter um recorte de um fenômeno. Para esse pesquisador, em uma pesquisa qualitativa de perspectiva etnográfica, o processo cíclico pode ser determinado coincidindo ou não com os limites temporais do fenômeno. O pesquisador pode escolher um dentre os vários ciclos que permeiam o contexto educacional ou propor um que contemple a natureza de seus dados.

De acordo com van Lier (2004), o objeto de estudo suscita e aponta uma série de ações tendo em vista suas peculiaridades. No caso da pesquisa qualitativa, considerando o contexto, o pesquisador e suas vivências, o cenário de pesquisa e o objeto de pesquisa, ela também aponta por ações complementares que auxiliam na condução da análise e coleta dos dados. A pesquisa qualitativa usa métodos múltiplos para uma rica coleta de dados que se estende ao universo tecnológico. Nesse ambiente, ela proporciona ao pesquisador uma descrição contextualizada e situada dos dados na ordem da 


\section{Revista do SELL \\ v. $4, n^{\circ} .1$ \\ ISSN: $1983-3873$}

compreensão da experiência ou da relação humana em meio a um sistema tecnológico (MANN; STEWART, 2000).

No caso de uma pesquisa qualitativa ter ambientes virtuais de aprendizagem como cenário para coleta de dados, Mann; Stewart (2000) defendem que a literatura transdisciplinar que documenta os aspectos da comunicação humana e seu comportamento no contexto on-line se constitui como uma relevância particular.

Nessa direção, a pesquisa qualitativa aponta para a indução como meio de interpretação dos dados, mas sempre considerando o processo e o foco dessa abordagem (DENZIN; LINCOLN, 2006, BICUDO, 2011). Quanto ao procedimento técnico, a abordagem qualitativa suscita o estudo de caso que, geralmente, envolve o estudo profundo e exaustivo de um ou poucos objetos, de maneira que se permita o seu amplo e detalhado conhecimento (GIL, 1991; van LIER, 2004).

Como síntese da base de dados, temos: a) análise do projeto pedagógico do CLIEAD e demais documentos; b) análise do design instrucional; e c) análise das interações registradas no AVA e das entrevistas informais. Os participantes da pesquisa foram: os professores, os tutores a distância, a pesquisadora e os alunos regularmente matriculados nessas disciplinas do CLIEAD. Ao todo, foram matriculados 158 alunos no curso.

O curso analisado e cenário da pesquisa, foi o 'CURSO DE LETRAS: LICENCIATURA EM INGLÊS E LITERATURAS DE LÍNGUA INGLESA' ofertado na modalidade a distância, que confere ao egresso do curso a titulação de Licenciado em Letras com Habilitação em Inglês e Literaturas de Língua Inglesa.

A coleta de dados aconteceu na aplicação do curso no período referente ao primeiro semestre letivo (2011-2). Nesse período foram ofertadas quatro disciplinas componentes curriculares do CLIEAD, a saber: Introdução à Educação a Distância, Introdução aos Estudos da Linguagem integrada à Prática Educativa I [PIPE 1], Língua Inglesa: Leitura Instrumental, Interdisciplinaridade e Construção do Saber, apresentadas na Figura 1 pelo fluxo curricular, retirado do PP, referente ao ano 1 e semestre 1 do CLIEAD.

Enfim, todas as interações ocorridas no ambiente dessas disciplinas foram registradas e se constituíram corpus de nossa pesquisa. Sendo assim, o universo da amostra compreendeu os registros das interações postadas no AVA, relativas a oferta 


\section{Revista do SELL}

v. $4, n^{\circ} .1$

ISSN: $1983-3873$

dessas quatro disciplinas pedagógicas do curso, além da organização/disposição dessas disciplinas no design instrucional do CLIEAD.

\subsection{Analise dos dados}

Em relação ao projeto pedagógico, as condições para a Complexidade se estabeleceram de modo complementar, uma vez que o projeto se mostrou uma rede de elementos indissociavelmente ligados. Nesse caso, a união de diferentes elementos para alcançarem um propósito comum identifica a dinâmica que movimentou as ações no PP, no contexto da EAD on-line. Nesse sentido, o PP apresentou um conjunto de condições antagônicas, mas ao mesmo tempo complementares.

No que diz respeito ao design instrucional, não detectamos o mesmo equilíbrio encontrado no PP, no que se refere às condições para a emergência da Complexidade. Sabemos que todas elas se estabeleceram no design, umas em maior, outras em menor proporção.

Em relação às salas de aula on-line, as condições necessárias para a emergência da Complexidade se estabeleceram de modo mais complementar. No que se refere aos participantes, identificamos um grupo bastante diverso, uma vez que os alunos são atuantes das mais diversas áreas e apresentaram os mais diversos perfis e interesse ao ingressar no curso, além de inúmeras dificuldades no trato com a língua inglesa e com as tecnologias digitais. Por outro lado, a interação articulou essas diferenças, dificuldades e facilidades no sistema. Várias respostas inteligentes sugiram desse todo diverso no sentido de que houve trocas de informação, auxílio mútuo às dificuldades, compartilhamento de estratégias de aprendizagem etc.

Consideramos o contexto como uma interrelação de circunstâncias que acompanham um fenômeno ou evento e defendemos que, em um ambiente de aprendizagem, a contextualização se efetiva pela interação entre as pessoas. Sendo assim, no ambiente do CLIEAD, no entanto os dados mostraram que encontramos mais fatores contextuais que influenciaram negativamente (EAD como novidade, a falta de fluência em Inglês, falta de fluência digital, não disponibilização de material didático impresso, feedback circular do tutores, quantidade excessiva de atividades avaliativas) o ambiente de aprendizagem impedindo a emergência de um ambiente propício à aprendizagem no AVA do curso. 


\section{Revista do SELL}

v. $4, n^{\circ} .1$

ISSN: $1983-3873$

Sendo assim, apontamos esses seis fatores acima como os principais fatores inibidores da aprendizagem que desestabilizaram o curso enquanto sistema complexo e apareceram muito marcados em inúmeras discussões, por um bom tempo, levando muitos alunos a desistirem do curso.

\section{Considerações Finais}

Entendemos que a necessidade de os cursos a distancia, como o CLIEAD, serem planejados e organizados com antecedência os levam a desconsiderarem o seu contexto de aplicação. Ao ser entregues 'prontos', esses cursos tendem a não se adequarem ou adaptarem às condições locais, levando sua aplicação a equívocos e incoerências tais como oferta de curso de especificidade totalmente alheia aos interesses e necessidades do público ingressado, o que impede ou dificulta a adaptação e auto-organização do sistema, uma vez que tais cursos são edificados em estruturas fixas e rígidas de modo a não permitir alterações necessárias para adaptação.

Acreditamos que esse estudo possa contribuir para os interessados em questões de organização instrucional de ambientes para ensino e aprendizagem de línguas e, também, para formação de professores de línguas. Ele ainda pode contribuir, sobretudo, para os linguistas aplicados com interesse na área da Complexidade, mediação a distância e estudos colaborativos em linguagem no viés das análises sistemáticas.

A análise mostrou que, como os objetivos instrucionais sobre os conteúdos e práticas pedagógicas que comporiam as disciplinas do CLIEAD foram definidos muito tempo antes da aplicação do curso, havendo grande espaço de tempo entre a organização do PP e sua implementação. Depois de começadas as atividades e, ao ter conhecimento das reais características e interesses dos alunos ingressados no curso, acreditamos que objetivos instrucionais deveriam ter sido ajustados às necessidades de aprendizagem dos respectivos alunos.

Esse ajuste poderia ter sido feito na medida em que os alunos fossem evoluindo em sua compreensão do desenvolvimento do curso e do que significa um AVA. Percebemos, ainda, que no CLIEAD, ouve certa inversão de fatores que talvez tenha prejudicado ou, de certa forma, restringido muitas ações em prol de construir um ambiente propício à emergência de aprendizagem contextualizada. Ao invés de se pensar um design para os alunos, primeiramente, pensou-se os alunos para um design. 


\section{REFERÊNCIAS}

BARCELOS, A. M. F. (Org.). Linguística Aplicada: reflexões sobre ensino e aprendizagem de língua materna e língua estrangeira. Campinas: Pontes Editores, 2011. Coleção: Novas perspectivas em Linguística Aplicada. v. 13. 328p.

BICUDO, M. A. V. Aspectos da pesquisa qualitativa efetuada em uma abordagem fenomenológica. In: BICUDO, M. A. V. Pesquisa qualitativa segundo a visão fenomenológica. São Paulo: Cortez, 2011. p. 29-40.

BRAGA, J. C. F. A presença cognitiva em comunidades de aprendizagem on-line. In: PAIVA, V. L. M. O.; NASCIMENTO, M. Sistemas adaptativos complexos: língua(gem) e aprendizagem. Belo Horizonte: Faculdade de Letras da UFMG, 2009. p. 131-148.

DAVIS, B.; SUMARA, D. Complexity and education: inquiries into learning, teaching, and research. Mahwash, N.J: Lawrence Erlbaum, 2006.

DENZIN, N. K.; LINCOLN, Y. S. O planejamento da pesquisa qualitativa: teorias e abordagens. Tradução de Sandra Regina Netz. 2. ed. Porto Alegre: Artmed, 2006. 432 p.

FILATRO, A. Design instrucional contextualizado. 2. ed. São Paulo: Editora Senac São Paulo, 2007. 215 p. 2008. $174 \mathrm{p}$.

Design instrucional na prática. São Paulo: Pearson Education do Brasil,

FREIRE, M.; ABRAHÃO, M. H. V.; BARCELOS, A. M. F. (Org.) Linguística aplicada e contemporaneidade. São Paulo: Pontes Editores, 2005. 352 p.

KLEIMAN, A. B. O ensino de línguas no Brasil. In: PASCHOAL, M. S. Z.; CELANI, M. A. A. Linguística Aplicada: da aplicação da linguística à linguística transdisciplinar. São Paulo: Educ, 1992. p. 25-36.

KLEIMAN, A. B.; CAVALCANTI, M. C. O DLA: uma história de muitas faces, um mosaico de muitas histórias. In: KLEIMAN, A. B.; CAVALCANTI, M. C (Org.). Linguística Aplicada: suas faces e interfaces. Campinas - SP: Mercado de Letras, 2007. p. 9-26.

LEFFA, V. J. Transdisciplinaridade no Ensino de Línguas: a perspectiva das Teorias da Complexidade. Revista Brasileira de Linguística Aplicada, v. 6, n. 1, p. 27-49, 2006

LORENZ, E.N. The Essence of Chaos. Seattle: University of Washington Press, 1993

MANN, C.; STEWART, F. Internet communication and qualitative research: a handbook for researching online. London: Sage, 2000. 258 p.

MARQUESI, S. C.; ELIAS, V. M. S.; CABRAL, A. L. T. (Org.). Interações virtuais: perspectivas para o ensino de Língua Portuguesa a distância. São Carlos: Editora Claraluz, 2008. 208 p. 
MARTINS, A. C. S. A emergência de eventos complexos em aulas on-line e face-aface: uma abordagem ecológica. 2008. 189 f. Tese (Doutorado em Linguística Aplicada) Faculdade de Letras, Universidade Federal de Minas Gerais, Belo Horizonte, 2008.

MOITA LOPES, L. P. Linguística Aplicada e vida contemporânea: problematização dos construtos que têm orientado a pesquisa. In: MOITA LOPES, L. P. (Org.) Por uma Linguística Aplicada indisciplinar. São Paulo: Parábola Editorial, 2006. p. 85-108.

MOITA LOPES, L. P. Contextos institucionais em linguística aplicada: novos rumos. Revista Intercâmbio, v. 5, p. 3-14,1996.

MORAN, J. M. Ensino e aprendizagem inovadores com tecnologias audiovisuais e telemáticas. In: MORAN, J. M.; MASETTO, M. T.; BEHRENS, M. A. Novas tecnologias e mediação pedagógica. 14. ed. Campinas: Papirus, 2008. p. 11-66

MORIN, E. Introdução ao pensamento complexo. Lisboa: Piaget, 2003. 181 p.

PAIVA, V. L. M. O. Modelo fractal de aquisição de línguas. In: BRUNO, F. C. (Org.) Reflexão e prática em ensino/aprendizagem de língua estrangeira. São Paulo: Editora Clara Luz, 2005. p. 23-36. Disponível em: <http://www.veramenezes.com/modelo.htm>. Acesso em: 01 de ago. 2012.

Autonomia e complexidade: uma análise de narrativas de aprendizagem. In: FREIRE, M. M; ABRAHÃO, M. H. V; BARCELOS, A. M. F (Org.). Linguística Aplicada e contemporaneidade. São Paulo: Pontes ALAB, 2005a. p.135-153.

Caos, complexidade e aquisição de segunda língua. In: PAIVA, V. L. M. O.; NASCIMENTO, M. Sistemas adaptativos complexos: língua(gem) e aprendizagem. Belo Horizonte: Faculdade de Letras da UFMG, 2009. p. 187-204.

PAIVA, V. L. M. O.; NASCIMENTO, M. (Org.). Sistemas adaptativos complexos: língua(gem) e aprendizagem. Belo Horizonte: Faculdade de Letras da UFMG, 2009. 269 p.

RESENDE, L. A. S. Identidade e aprendizagem de inglês sob a ótica do caos e dos sistemas complexos. 2009. 305 f. Tese (Doutorado em Estudos Linguísticos) Faculdade de Letras, Universidade Federal de Minas Gerais, Belo Horizonte, MG, 2009.

SIGNORINI, I.; CAVALCANTI, M. C. Linguística Aplicada e transdisciplinaridade. Campinas: Mercado das Letras, 2004. 215 p.

SIGNORINI, I.; CAVALCANTI, M. C. Língua, linguagem e mediação tecnológica.

Trabalhos em Linguística Aplicada, Campinas, v. 49 n. 2, Jul. Dez, 2010. Disponível em: <http://www.scielo.br/scielo.php?script=sci_arttext\&pid=S0103-

$18132010000200007 \&$ Ing=en\&nrm=iso\&tlng=pt $>$. Acesso em: 17 abr. 2012.

SILVA, J. M. Revista Brasileira de Aprendizagem Aberta e a Distância. São Paulo, Agosto, 2002. Disponível em: 
<http://www.abed.org.br/revistacientifica/Revista_PDF_Doc/2002_Teoria_Distancia_Trans acional_Michael_Moore.pdf>. Acesso em: 9 fev. 2010.

SILVA, M. Sala de aula interativa. 3. ed. São Paulo: Edições Loyola, 2012. 220 p.

SOBRAL, A. Reflexões sobre as concepções de leitura de alunos de Mestrado. In: BARCELOS, A. M. F. (Org.). Linguística Aplicada: reflexões sobre ensino e aprendizagem de língua materna e língua estrangeira. Campinas: Pontes Editores, 2011. Coleção: Novas perspectivas em Linguística Aplicada. v. 13 p. 47-66.

\section{SOUZA, V. V. S. Dinamicidade e adaptabilidade em comunidades virtuais de} aprendizagem: uma textografia à luz do paradigma da complexidade. 2011. $256 \mathrm{f}$. Tese (Doutorado em Estudos Linguísticos) - Faculdade de Letras, Universidade Federal de Minas Gerais, Belo Horizonte, MG, 2011.

TEIXEIRA, A. G. D. Difusão tecnológica no ensino de línguas: o uso de computadores portáteis nas aulas de Língua Portuguesa sob a ótica da complexidade. 2012. 207f. Tese (Doutorado em Estudos Linguísticos) - Faculdade de Letras, Universidade Federal de Minas Gerais, Belo Horizonte, MG, 2012.

Van LIER, L. The ecology and semiotics of language learning: a sociocultural perspective. Kluwer Academic Publishers, 2004. 248 p.

VENTROMILLE-CASTRO, R. A entropia sócio-interativa e a sala de aula de (formação de professores de) língua estrangeira: reflexões sobre um sistema complexo. In: PAIVA, V. L. M. O.; NASCIMENTO, M. Sistemas adaptativos complexos: língua(gem) e aprendizagem. Belo Horizonte: Faculdade de Letras da UFMG, 2009. p. 113-130 